\title{
In vitro aldose reductase inhibitory potential of fractions isolated from Potentilla fulgens roots
}

\author{
Suktilang Majaw ${ }^{1 *}$, Donkupar Syiem ${ }^{2}$ \\ ${ }^{1}$ Department of Biotechnology and Bioinformatics, North-Eastern Hill University, Shillong, 793022, Meghalaya, India. \\ ${ }^{2}$ Department of Biochemistry, North-Eastern Hill University, Shillong, Meghalaya, 793022, India.
}

\begin{tabular}{l}
\hline ARTICLE INFO \\
\hline Article history: \\
Received on: 03/05/2016 \\
Revised on: $13 / 06 / 2016$ \\
Accepted on: 07/07/2016 \\
Available online: $30 / 08 / 2016$ \\
\hline Key words: \\
Aldose reductase, Potentilla \\
fulgens, terpenoid/phenolic \\
fraction, TLC F-V fraction.
\end{tabular}

\begin{abstract}
The present study was investigated to identify the active fraction of $P$. fulgens with aldose reductase (AR) inhibitory potential. AR is the rate limiting step of polyol pathway implicated in the onset of chronic complications of diabetes. In this study, kidney homogenates of normoglycemic and diabetic mice were used as a source of AR enzyme preparation for in vitro analysis. The Terpenoid/Phenolic (TP) fraction of P. fulgens had the lowest $\mathrm{IC}_{50}$ value $(0.152 \mathrm{mg} / \mathrm{ml})$ for $\mathrm{AR}$ than the other fractions. TP fraction was separated using thin layer chromatography (TLC) and separated TLC fractions were tested for their AR inhibitory activity. Among the TLC fractions, F-V had the lowest $\mathrm{IC}_{50}$ value $(0.156 \mathrm{mg} / \mathrm{ml})$ and was characterized further using High Performance Liquid Chromatography (HPLC), Infra-Red (IR) Spectroscopy and Mass Spectroscopy (MS). F-V showed absorption maxima at $\lambda 230 \mathrm{~nm}$ and $\lambda 280 \mathrm{~nm}$. HPLC profile of this fraction showed the presence of one prominent peak with a retention time of 1.621 . IR spectra of the prominent peak indicated the presence of aromatic group which is phenolic in nature. MS of the prominent peak showed $\mathrm{m} / \mathrm{z}$ ratio of 458.8 . The active fraction isolated from $P$. fulgens has been shown to inhibit AR in normoglycemic and diabetic mice.
\end{abstract}

\section{INTRODUCTION}

Aldose reductase (AR) is the first and rate-limiting enzyme of the polyol pathway which converts glucose to sorbitol in the presence of NADPH as a cofactor. AR under euglycemic condition plays a minor role in glucose metabolism which accounts for approximately $3 \%$ of glucose utilization whereas under hyperglycemic condition more than $30 \%$ of glucose is metabolized through this pathway (Morrison et al., 1970; YabeNishimura, 1998; Alexiou et al., 2009).

Increased glucose flux through the polyol pathway has been associated with the pathogenesis of diabetic complications via several potential mechanisms (Steele et al., 1993; Van den Enden et al., 1995; Hamada and Nakamura, 2004). Therefore,

* Corresponding Author

Suktilang Majaw, Department of Biotechnology and Bioinformatics, North-Eastern Hill University, Shillong, 793022, Meghalaya, India mail id:smajaw.nehu@gmail.com / smajaw@nehu.ac.in inhibition of $\mathrm{AR}$ represents an attractive strategy for prevention of diabetic complications. Although a wide variety of compounds have been identified to inhibit the AR, however, very few of them are known to exhibit sufficient therapeutic efficacy (Pathania et al., 2013). New candidate drugs have poor pharmacokinetic properties and/ or unacceptable side effects (Foppiano and Lombardo, 1997; Costantino et al., 1999; Schemmel et al., 2010). Hence, there is a need to develop new inhibitors against AR taking into account the efficacy, selectivity and safety issues. For diabetes and its complications, natural compounds of therapeutic value are highly sought after (Hung et al., 2012). There is an increased interest in recent times to identify sources using medicinal plants for their therapeutic properties. As plant products are mostly free from adverse effects (Rao et al., 2010), they are used as a source of traditional medicine in treating various ailments including diabetes mellitus. Plant extract and their derivatives like phenolics and flavonoid compounds are active inhibitors to AR enzyme (Lindstad et al., 1994; Reddy et al., 2011; Veeresham et al., 2013). 
We have earlier evaluated Potentilla fulgens L. (family: Rosaceace) and found that the crude extract have the potential to inhibit AR at the enzymatic level in animal model (Syiem and Majaw, 2010). P. fulgens, commonly found at higher altitude of Khasi Hill, Meghalaya, India have also been reported to possess hypoglycemic, anti-hyperglycemic, anti-tumor, anti-hypolipidemic and antioxidant activity (Syiem et al., 2002; Syiem et al., 2003; Syiem et al., 2009a; Syiem et al., 2009b). In this study we have isolated active component possessing in vitro $\mathrm{AR}$ inhibitory activity from the fractions of $P$. fulgens root extract with lowest inhibitory concentration ( $\mathrm{IC}_{50}$ value) using techniques such as TLC, HPLC, UV-Vis, IR and MS analysis.

\section{MATERIALS AND METHODS}

\section{Chemicals and reagents}

Alloxan, DL-glyceraldehyde was procured from Sigma Chemical Co. (USA), nicotinamide adenine dinucleotide phosphate (NADPH), hexane, ethylacetate, methanol, chloroform, acetonitrile, was from Sisco Research Laboratories (SRL), India. Other chemicals were of analytical grade obtained from Qualigens and SRL, India.

\section{Experimental animal}

Healthy, Swiss albino mice of approximately 6 months old were used for the study. Mice were housed in a room kept under controlled conditions with temperature maintained at $22^{\circ} \mathrm{C}$ on a $12 \mathrm{~h}$ light: $12 \mathrm{~h}$ dark cycle and were fed with balanced mice feed obtained from Pranav Agro Industries Ltd, New Delhi. All efforts were made to minimize both the number of animals used and unwanted stress or discomfort to the animals throughout the experimental procedures.

\section{Plant material}

P. fulgens L. was collected from Shillong peak area of Meghalaya and identified by Dr. P. Gurung, Department of Botany, North-Eastern Hill University, Shillong (voucher number 464). The roots were separated, weighed, washed, shredded and oven dried at $40^{\circ} \mathrm{C}$. It was then powdered and utilized for preparation of plant extracts.

\section{Preparation of plant extracts}

(a) The powder was homogenized and extracted with aqueous-methanolic solution (1:4). The mixture was filtered and the filtrate was lyophilized and was used as a crude extract as per the method of Harborne (1998).

(b) Terpenoid/phenolic (TP) fraction was obtained by evaporating the filtrate (from step a) to $1 / 10$ volume $\left(40^{\circ} \mathrm{C}\right.$ ) followed by acidification with $2 \mathrm{M} \mathrm{H}_{2} \mathrm{SO}_{4}$ to $\mathrm{pH}$ 0.89 . This was further, extracted with chloroform $(\times 3)$. The chloroform layer was separated from the aqueous layer. The chloroform layer was further evaporated to yield the TP fraction.

(c) The aqueous layer obtained in step (b) was basified to $\mathrm{pH}$ 10 with ammonia solution and further extracted with chloroform: methanol (3:1, twice). The chloroformmethanol layer was separated and evaporated to yield the major alkaloid (MA) fraction. Quaternary alkaloid (QA) fraction was obtained by evaporating the aqueous layer followed by extraction with methanol.

The yield percentage of each extract was calculated as per the equation given below:

$$
\text { Yield Percentage (\%) }=\frac{\text { Mass of extract }}{\text { Mass of sample }} \times 100 \%
$$

\section{Experimental Design}

For AR inhibitory activity, varying concentration of crude extract of $P$. fulgens was tested on AR using kidney homogenate from normoglycemic mice as per the method of Guzmán and Guerrero (2005) with modification. Crude extract of $P$. fulgens was tested to compare the analysis with TP, MA and QA fractions of $P$. fulgens roots.

The crude extract and the fraction exhibiting the lowest $\mathrm{IC}_{50}$ value were also tested for AR inhibitory activity using kidney enzyme solution of diabetic mice in order to compare the $\mathrm{IC}_{50}$ value against AR in kidney of normoglycemic mice. The selected fraction was further separated using TLC and the subsequent separated TLC fractions were tested for their inhibitory effect against AR. The TLC fraction showing the maximum inhibitory activity was selected for HPLC separation and then, IR and MS analysis was performed for the isolated HPLC peak.

\section{Preparation of diabetic mice}

Animals were administered alloxan monohydrate prepared in acetate buffer $(0.15 \mathrm{M}, \mathrm{pH} 4.5)$ via intraperitoneal route (Syiem et al., 2002). Prior to administration, mice were fasted overnight but given water ad libitum. The blood samples collected were analyzed for glucose levels employing glucostix with the blood glucometer. Normoglycemic mice have blood glucose level in the normal range $(80-120 \mathrm{mg} / \mathrm{dl})$ and mice with more than 3-4 fold increased in blood glucose were considered diabetic.

\section{Tissue preparation}

The kidney tissue was homogenized in 2.5 volumes of cold 0.225 M sucrose-Tris buffer (pH 7.4), and centrifuged at 9000 $\mathrm{xg}$ for $15 \mathrm{~min}$. The supernatant was further centrifuged at 16,000 $\mathrm{xg}$ for $30 \mathrm{~min}$. The pellet was discarded and the supernatant was used as enzyme preparation for AR.

\section{In vitro $\mathrm{AR}$ inhibition assay}

Inhibition of $\mathrm{AR}$ was assayed according to Haraguchi et al., 1997 with some modifications. The reaction mixture was prepared at $25^{\circ} \mathrm{C}$, in a total volume of $1 \mathrm{~mL}$, containing $50 \mathrm{mM}$ Na-phosphate buffer ( $\mathrm{pH}$ 6.5), 0.2 mM NADPH, $100 \mu \mathrm{l}$ enzyme preparation and $100 \mathrm{mM}$ dl-glyceraldehyde as a substrate with or without crude extract/fractions. The reaction was initiated by 
addition of NADPH and absorbance measurements were taken at $\lambda 340 \mathrm{~nm}$. $1 \mathrm{M} \mathrm{NaHCO}$ sas added at the end of the $30 \mathrm{~min}$ incubation period. A negative control was prepared in 5\% DMSO in Na-phosphate buffer ( $\mathrm{pH}$ 6.5). The enzyme inhibition (\%) was calculated using following formula:

$$
\text { Inhibition } \%=\frac{\Delta \text { Abs. (Negative Control) }-\Delta \text { Abs. (Extract) }}{\Delta \text { Abs. (Negative Control) }} \times 100
$$

Where, Abs. is the absorbance

The experiments were run in triplicate and the concentration of extracts required to inhibit $50 \%\left(\mathrm{IC}_{50}\right)$ of the $\mathrm{AR}$ activity were determined by linear regression analysis between the inhibition percentage versus the extract concentration by using the Excel program. Protein concentrations were determined according to the method of Bradford (1976) using bovine serum albumin (BSA) as the standard.

\section{Thin layer chromatography}

The TP fraction showed the lowest $\mathrm{IC}_{50}$ value and was further separated by TLC (Wagner and Bladt, 1996) using silica gel Grade GF-254 with $\mathrm{CaSO}_{4}$ as binder using solvent system, Hexane: ethyl acetate (1:1). It was visualized using $10 \%$ ethanolic ferric chloride followed by heating the plates at $100^{\circ} \mathrm{C}$. Individual fractions were separated based on their $\mathrm{R}_{\mathrm{f}}$ values.

$$
\mathrm{R}_{\mathrm{f}}=\quad \frac{\text { Distance travelled by the sample }}{\text { Distance Travelled by the solvent }}
$$

Separated fractions were re-run on the same solvent system to check for their homogeneity. Fractions showing only one spot were tested for AR inhibitory activity. TLC fraction with lowest $\mathrm{IC}_{50}$ value was selected for further studies.

\section{HPLC profile of TLC fraction}

The selected TLC fraction was pooled through repeated separation, dissolved in methanol and centrifuged at $3000 \mathrm{rpm}$ to sediment and remove silica gel. The supernatant evaporated in an oven (below $40^{\circ} \mathrm{C}$ ) and the obtained sample $(1 \mathrm{mg} / \mathrm{ml})$ was dissolved in $100 \%$ methanol followed by filtration through a membrane filter (pore size of $0.45 \mu \mathrm{m} / 13 \mathrm{~mm}$ ).

The filtrate was scanned under UV to determine the $\lambda \max$ using Cary win-50 UV/Vis spectrophotometer and then applied to HPLC (Waters Pvt Ltd) using C-18 symmetry (bondapak), $3.9 \times 150 \mathrm{~mm}$, reverse phase column. Sample elution using isocratic mode was carried out with the mobile phase comprising acetonitrile and water (9:1), flow rate was maintained at $1 \mathrm{ml} / \mathrm{min}$ with a pressure of $800 \mathrm{psi}$ and detected at $\lambda 230 / 280$ nm using HPLC-2487 detector. The sample eluted from the HPLC column was collected using a fraction collector (WFC-44274).

\section{IR spectra and MS analysis of HPLC fraction}

The selected HPLC fraction was analyzed as a neat film between two potassium bromide $(\mathrm{KBr})$ plates using FT-IR Spectrum BX (Perkin Elmer Infrared Spectrophotometer). The IR spectrum was recorded between 4000-400 wave numbers $\left(\mathrm{cm}^{-1}\right)$.

The major peak of the TLC fraction separated by HPLC were pooled and concentrated. The concentrated sample was dissolved in methanol and $20 \mu \mathrm{l}$ loaded onto Waters-MS using an Xterra MS. Micromass ZQ (Multimode Ionization) from Waters was used to generate the mass spectra of the sample. Each peak corresponds to the $\mathrm{m} / \mathrm{z}$ value of the fragmented sample. Thus, the peak with highest $\mathrm{m} / \mathrm{z}$ value was taken as the parent molecular ionmass.

\section{Total polyphenolic content and flavonoid content}

The total polyphenolic content of TP fraction was determined following the method of Miraliakbari and Shahidi (2008). $200 \mu \mathrm{l}$ of TP fraction dissolved in methanol and mixed with $300 \mu \mathrm{l}$ of $3 \% \mathrm{HCl}$ was vortexed and allowed to stand for 3 min. $100 \mu \mathrm{l}$ of acidified mixture was added to $1 \mathrm{ml}$ of $3 \%$ sodium bicarbonate followed by $20 \mu \mathrm{l}$ of Folin-Ciocalteu reagent and allowed to stand at room temperature for $30 \mathrm{~min}$. Absorbance was measured at $\lambda 760 \mathrm{~nm}$. The results are calculated in $\mathrm{mg} / \mathrm{ml}$ gallic acid equivalents (GAE) which is a reference standard for this method. Data were represented as mean \pm standard error mean (SEM) using 5 separate experiments.

Flavonoid content of TP fraction was determined by the method of Chang et al., (2002). $10 \mathrm{mg}$ of quercetin (standard)/TP fraction $(25-100 \mu \mathrm{g} / \mathrm{mL})$ dissolved in $80 \%$ ethanol. $0.5 \mathrm{~mL}$ of standard/TP fraction were mixed with $1.5 \mathrm{~mL} 95 \%$ ethanol and then treated with $0.1 \mathrm{~mL}$ of $10 \%$ aluminium chloride, $0.1 \mathrm{~mL}$ of $1 \mathrm{M}$ potassium acetate followed by $2.8 \mathrm{~mL}$ of distilled water. Absorbance was measured at $\lambda 415 \mathrm{~nm}$. Data were represented as mean \pm standard error mean (SEM) using 5 separate experiments.

\section{RESULTS AND DISCUSSION}

We found that the yield of crude extract (w/w from dried starting material) was $7.76 \%$ whereas the yield percentage of the TP, MA and QA fractions was $0.20 \%, 0.78 \%$ and $17.22 \%$ respectively.

AR in vitro inhibition assay was performed using enzyme solution of kidney tissue from normoglycemic and diabetic mice. Protein concentration of enzyme solution from normoglycemic and diabetic kidney was $8 \mathrm{mg} / \mathrm{ml}$ and $8.4 \mathrm{mg} / \mathrm{ml}$ respectively. The crude extract of $P$. fulgens roots was found to have $\mathrm{IC}_{50}$ value of $0.116 \mathrm{mg} / \mathrm{ml}$ and $0.133 \mathrm{mg} / \mathrm{ml}$ in kidney of normoglycemic and diabetic mice respectively (Table 1-2). The TP fraction showed $\mathrm{IC}_{50}$ value of $0.1522 \mathrm{mg} / \mathrm{ml}$ while MA and QA fractions exhibited $\mathrm{IC}_{50}$ concentration of $0.1829 \mathrm{mg} / \mathrm{ml}$ and $0.602 \mathrm{mg} / \mathrm{ml}$ respectively in kidney tissue of normoglycemic mice (Table 1). 
Table 1: Inhibitory activity of crude extract, major alkaloid (MA), quaternary alkaloid (QA), terpenoid/phenolic (TP) and TLC separated fractions (F-I to FVI) of $P$. fulgens against AR of kidney tissue from normoglycemic mice.

\begin{tabular}{clc}
\hline Sl.No. & Extracts & IC $_{\mathbf{5 0}}(\mathbf{m g} / \mathbf{m l})$ \\
\hline $\mathbf{1}$ & Crude extract & 0.116 \\
$\mathbf{2}$ & MA Fraction & 0.1829 \\
$\mathbf{3}$ & QA Fraction & 0.602 \\
$\mathbf{4}$ & TP Fraction & 0.152 \\
$\mathbf{5}$ & Fraction F-I & 0.354 \\
$\mathbf{6}$ & Fraction F-II & 0.737 \\
$\mathbf{7}$ & Fraction F-III & 0.265 \\
$\mathbf{8}$ & Fraction F-IV & 0.328 \\
$\mathbf{9}$ & Fraction F-V & 0.157 \\
$\mathbf{1 0}$ & Fraction F-VI & 0.216 \\
\hline
\end{tabular}

Data for $\mathrm{IC}_{50}$ values are the average of three independent experiments.

Since, the $\mathrm{IC}_{50}$ value of TP fraction was lowest compared to MA and QA fractions, TP fraction was further tested for its AR inhibitory assay using kidney tissue of diabetic mice, and the $\mathrm{IC}_{50}$ value was found to be $0.1573 \mathrm{mg} / \mathrm{ml}$ (Table 2).

Table 2: Inhibitory activity of crude extract, terpenoid/phenolic (TP) and TLC separated fraction F-V of $P$. fulgens against AR of kidney tissue from diabetic mice.

\begin{tabular}{clc} 
mice. & \multicolumn{1}{c}{ Extracts } & IC $_{\mathbf{5 0}}(\mathbf{m g} / \mathbf{m l})$ \\
\hline Sl.No. & & 0.133 \\
$\mathbf{1}$ & Crude extract & 0.1573 \\
$\mathbf{2}$ & TP Fraction & 0.1654 \\
$\mathbf{3}$ & Fraction F-V &
\end{tabular}

Data for $\mathrm{IC}_{50}$ values are the average of three independent experiments.

As observed in this study, the $\mathrm{IC}_{50}$ value of crude extract was found to be lowest compared to that of the TP, MA and QA fractions. This may be due to the synergistic effect of the compounds present in the crude extract. It is not always possible, however, to isolate the bioactive compounds/agents in a plant and cases are known where attempts at such isolation have resulted in loss of activity due to instability of the compounds (Harborne, 1992). It is also likely that the chemical entities degrade during the fractionation process. Many reports and reviews have highlighted similar observations that specific activities/function associated with a plant or its extract is lowered following fractionation and purification process as seen for Zingiber officinale (Rates, 2001) and ginseng (Hamburger and Hostettmann, 1991; Rates, 2001). The crude extract of $P$. fulgens showed lowest $\mathrm{IC}_{50}$ as it may contain complex mixture and inert components which are known to influence stability, bioavailability and excretion of the active component. The $\mathrm{IC}_{50}$ concentration for in vitro $\mathrm{AR}$ inhibitory assay showed by the crude extract and TP fraction was found to be higher in diabetic mice than in normorglycemic mice, implying lowered inhibitory efficacy. Previous studies have shown that AR isolated from diabetic or hyperglycemic tissues is less susceptible to inhibition and is kinetically different from the enzyme purified from normoglycemic or euglycemic human or animal tissues (Das and Srivastava, 1985; Srivastava et al., 1985; 1986a, b; Chandra et al., 2002). These changes in the inhibitor sensitivity and the kinetic properties have been reported upon thiol oxidation of purified protein in vitro, suggesting that diabetic changes in AR may be due to redox modification of its cysteine residues (Cappiello et al., 1996). Thus, the higher $\mathrm{IC}_{50}$ concentration observed in this study may possibly be due to similar reason where diabetic condition results in lower susceptibility, hence, require higher concentration of extract to inhibit the enzymes of the pathway. Among the TP, MA and QA fractions, the $\mathrm{IC}_{50}$ concentration of TP fraction for AR was the lowest, hence, TP fraction was selected for further separation using TLC. As shown in Figure 1, six TLC fractions were observed with $R_{f}$ of $0.95,0.84$, $0.75,0.67,0.61$ and 0.48 corresponding to fraction F-I, F-II, F-III, F-IV, F-V, F-VI respectively. The separated fractions corresponding to different $\mathrm{R}_{\mathrm{f}}$ values were further tested for their AR inhibitory activity (Table 1 ). The $\mathrm{IC}_{50}$ value of TLC fractions F-I, F-II, F-III, F-IV, FV and F-VI were found to be 0.354, 0.737, $0.265,0.328,0.157$ and $0.216 \mathrm{mg} / \mathrm{ml}$ respectively. Since, F-V among the TLC fractions exhibited the lowest $\mathrm{IC}_{50}$ value, hence, TLC fraction F-V was tested for AR inhibitory activity of the kidney $\mathrm{AR}$ of diabetic mice where the $\mathrm{IC}_{50}$ value was found to be $0.1654 \mathrm{mg} / \mathrm{ml}$ as shown in Table 2 .

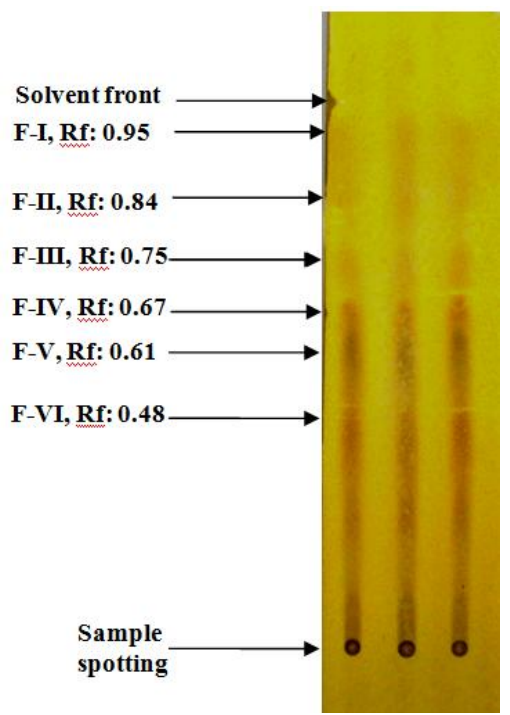

Fig. 1: Thin layer chromatography analysis of the TP fraction of $P$. fulgens. F-I to F-VI are Separated fractions based on their $\mathrm{R}_{\mathrm{f}}$

TLC fraction $\mathrm{F}-\mathrm{V}$ showed the lowest $\mathrm{IC}_{50}$ concentration compared to the other TLC fractions and hence, was selected for UV, HPLC, IR and MS analysis. Total polyphenolic and flavonoid content of TP fraction was also determined to confirm the presence of phenolics and flavonoid in the fraction.The total phenolic content of the TP fraction of $P$. fulgens was found to be $54 \mathrm{mg} / \mathrm{g}$ dry material with flavonoid content being $31 \mathrm{mg} / \mathrm{g}$ of dry material respectively (Table 3 ).

Table 3: Total polyphenolic and flavonoid content of the TP fraction of $P$. fulgens roots (mg/g of dry material).

\begin{tabular}{clc}
\hline SI No. & Content & Mean \pm SEM \\
\hline $\mathbf{1}$ & Total phenolic Content (mg/g of dry material) & $54 \pm 0.56$ \\
$\mathbf{2}$ & Flavonoid content (mg/g of dry material) & $31 \pm 0.38$ \\
\hline
\end{tabular}

Values represented as Mean \pm SEM. Mean $(\mathrm{M})$ values are obtained from 5 separate experiments; SEM ( \pm ) Standard Error Mean. 
The UV spectrum of TP fraction showed absorption maxima at $\lambda 205 \mathrm{~nm}, 230 \mathrm{~nm}, 250 \mathrm{~nm}$ and $280 \mathrm{~nm}$ (Figure 2a) whereas the isolated active entity $(\mathrm{F}-\mathrm{V})$ exhibited absorption maxima in the UV range at $\lambda 230 \mathrm{~nm}$ and $280 \mathrm{~nm}$ (Figure $2 \mathrm{~b}$ ).

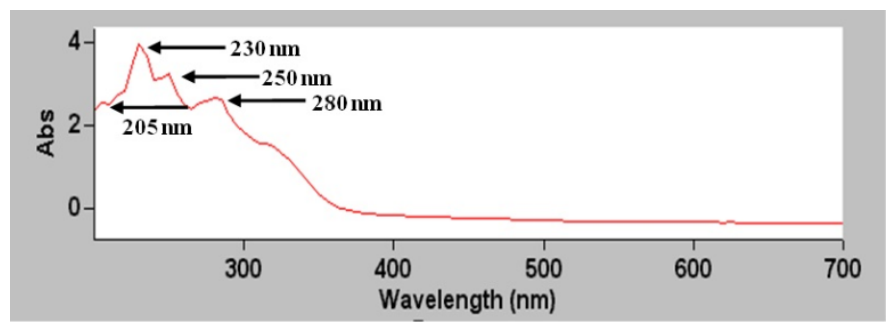

Fig. 2a: UV/Vis-spectra of TP fraction of $P$. fulgens using Cary UV-50 spectrophotometer with wavelength $(\lambda)$ scan ranging from 200 to $700 \mathrm{~nm}$.

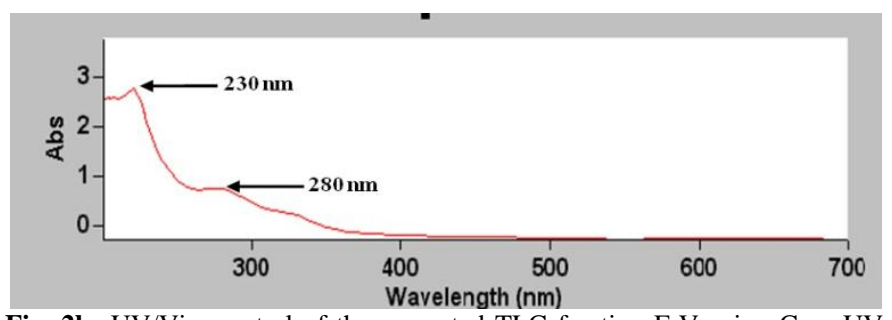

Fig. 2b: UV/Vis-spectral of the separated TLC fraction F-V using Cary UV50 spectrophotometer with wavelength $(\lambda)$ scan ranging from 200 to $700 \mathrm{~nm}$.

HPLC chromatographic profile of TLC fraction F-V showed the presence of one prominent peak with a retention time of 1.621 and 3 minor peaks with retention time of 1.933, 2.787 and 3.449 respectively (Figure 3 ). This shows that the active TLC fraction (F-V) was not completely resolved by TLC. The most prominent peak in HPLC was selected for IR and MS study so as to generate a spectral finger print of this entity.

Figure 4 shows IR spectra of the major HPLC peak and the following absorption linear characteristics wave number (v) was observed. IR (KBr) $\mathrm{cm}^{-1}$ of $3416,2925,1633,1566,1420$, 1096 and 605, correspond to the hydroxyl groups of alcohols and phenols recognized from their typical $\mathrm{O}-\mathrm{H}$ stretching absorptions in the region around $3650-3200 \mathrm{~cm}^{-1}$ which is left of the aliphatic $\mathrm{C}-\mathrm{H}$ stretch (around $2925 \mathrm{~cm}^{-1}$ ). The peak $1633 \mathrm{~cm}^{-1}$ may indicate $\mathrm{C}=\mathrm{O}$ and $1566 \mathrm{~cm}-1$ may be due to $\mathrm{C}=\mathrm{C}$ aromatic ring (Yam et al., 2010). Kudzin and Nord (1951) relate the absorption band at $1420 \mathrm{~cm}^{-1}$ to deformation vibrations of the $\mathrm{CH}$-group in the aromatic ring. The peak $1096 \mathrm{~cm}^{-1}$ may be due to $\mathrm{C}-\mathrm{O}$ stretching of phenols (Dick et al., 2002). The signal at $605 \mathrm{~cm}^{-1}$ indicates $-\mathrm{OH}$ deformation in phenols (Ahmad et al., 2010). IR spectra indicate the presence of aromatic group which is phenolic in nature.

While the mass profile of the HPLC fraction corresponding to retention time of 1.621 exhibited a $\mathrm{m} / \mathrm{z}$ ratio of
454.8 (Figure 5). It may be pertinent to mention that biological entities largely follow the Lipinsky's rule (Lipinsky et al., 1997). The rule was formulated by Christopher A. Lipinski in 1997, based on the observation that most medication drugs are relatively small and lipophilic molecules. The rule describes molecular properties important for a drug's pharmacokinetics in the human body, including their absorption, distribution, metabolism, and excretion ("ADME"). The rule is important for drug development where a pharmacologically active lead structure is optimized step-wise for increased activity and selectivity, as well as drug-like properties as described by Lipinski's rule and one of the criteria was that the molecular weight of the active component should not be greater than 500 Da. Thus, the active component separated through HPLC possesses the qualities of active drug. These and similar studies attest to the continuing value of natural products as templates for drug design.

It may be mentioned that other studies have shown among the wide range of natural products or secondary metabolites that the phenolic compounds exhibit a wide range of biological activity in particular potential anti-diabetic properties (Brahmachari and Gorai, 2006a,b; Brahmachari, 2009). Polyphenolic are ubiquitous in the plant kingdom and are classified into three major groups: phenolic acids, flavonoids, and tannins (Wrolstad et al., 2005). Phenolic acids include hydroxybenzoic, hydroxyphenylacetic, and hydroxycinnamic acids. The family of flavonoids includes mainly flavonols, flavanols, flavones, flavanones, isoflavones and anthocyanins. According to Hulse et al. (1980) polyphenolics are a set of phytochemicals with the molecular weight ranging from 150-30,000 Da, mainly consisting of phenolic compounds and their derivatives, flavonoids and tannins.

Flavonoids are benzo- $\gamma$-pyrone derivatives containing several hydroxyl groups attached to ring structures $\mathrm{C}_{6}-\mathrm{C}_{3}-\mathrm{C}_{6}$. They include: flavonols (e.g., quercetin, kaempferol), flavones (e.g., luteolin), flavanols (e.g., catechin), isoflavones (e.g., genistein). Flavonoids are known to exhibit an inhibitory effect on AR (Haraguchi et al., 1996; Kim et al., 2001; Patra and Chua, 2010). Detection of the polyphenolics has been commonly based on the absorptive measurement at characteristic wavelengths. All polyphenolics absorb in the UV region (Robards and Antolovich, 1997). The result of the UV spectrum indicated that the active entity may fall in the flavanols group with absorption maxima at $\lambda 230 \mathrm{~nm}$ and $\lambda 280 \mathrm{~nm}$.

Flavanols (sometimes referred to as Flavan-3-ols) are a class of flavonoids that use the 2-phenyl-3,4-dihydro-2H-chromen3-ol skeleton. Catechin and epicatechin with epigallocatechin and gallocatechin are some of the most common examples of flavanols. Other species of Potentilla like $P$. alba have been found to contain catechin (Gritsenko and Smik, 1977); epicatechin has been detected in $P$. erecta (Vennat et al., 1994), $P$. anserine hasepigallocatechin (Kombal and Glasl, 1995). Thus, P. fulgens also have high possibility of possessing these flavonols group, thus, further studies are required for confirmation. 


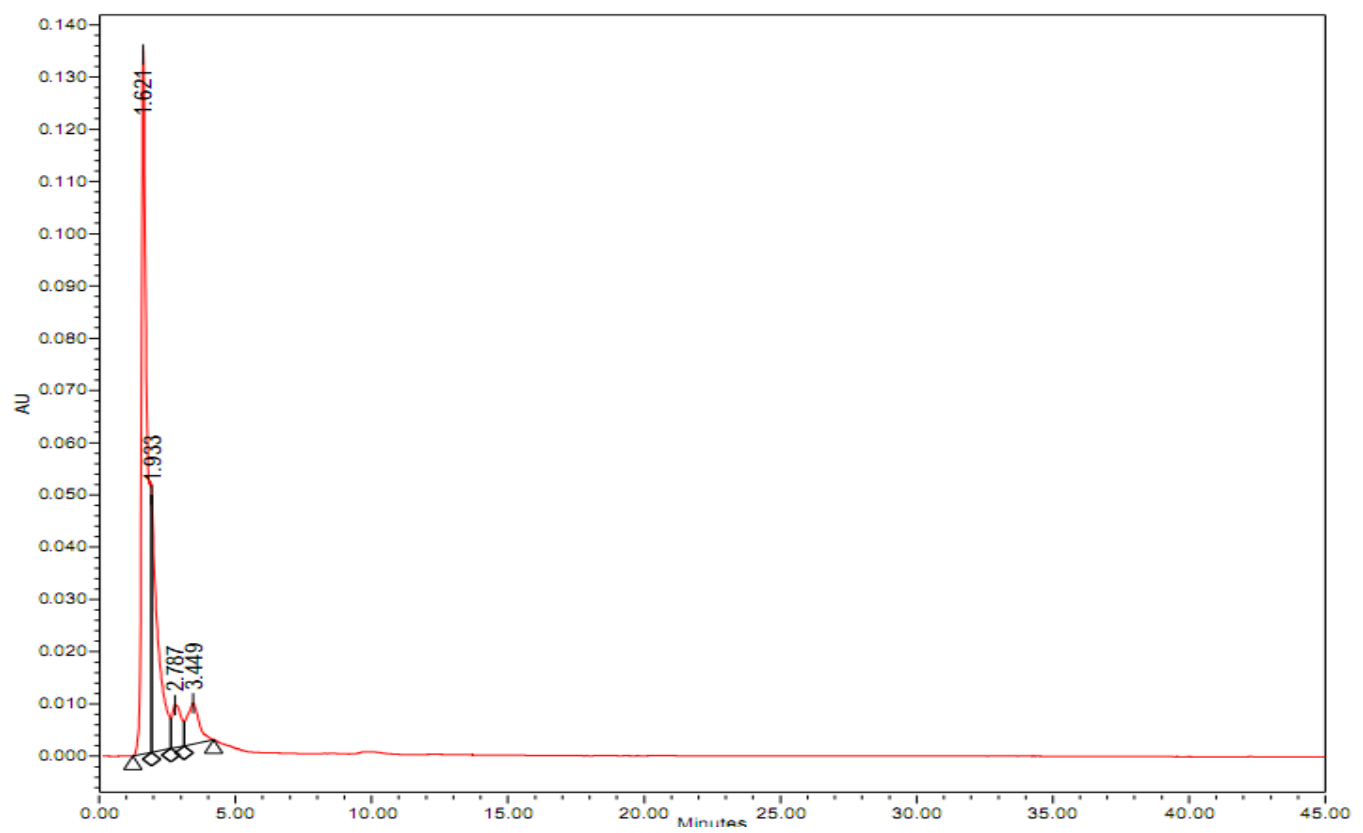

\begin{tabular}{cccccc}
\hline SI No. & Retention time $(\min )$ & Area & \% Area & Height & Peak Type \\
\hline $\mathbf{1}$ & 1.621 & 1989982 & 62.47 & 134663 & Unknown \\
$\mathbf{2}$ & 1.933 & 756485 & 23.75 & 49255 & Unknown \\
$\mathbf{3}$ & 3.449 & 245244 & 7.70 & 7841 & Unknown \\
$\mathbf{4}$ & 2.787 & 193915 & 6.09 & 8199 & Unknown \\
\hline
\end{tabular}

Fig. 3: HPLC profile of the separated TLC fraction (F-V) using C-18 reverse phase column $(3.9$ x $150 \mathrm{~mm})$. Solvent used: Acetonitrile and water in the ratio of 9:1. Detection: at $\lambda 230 / 280$.

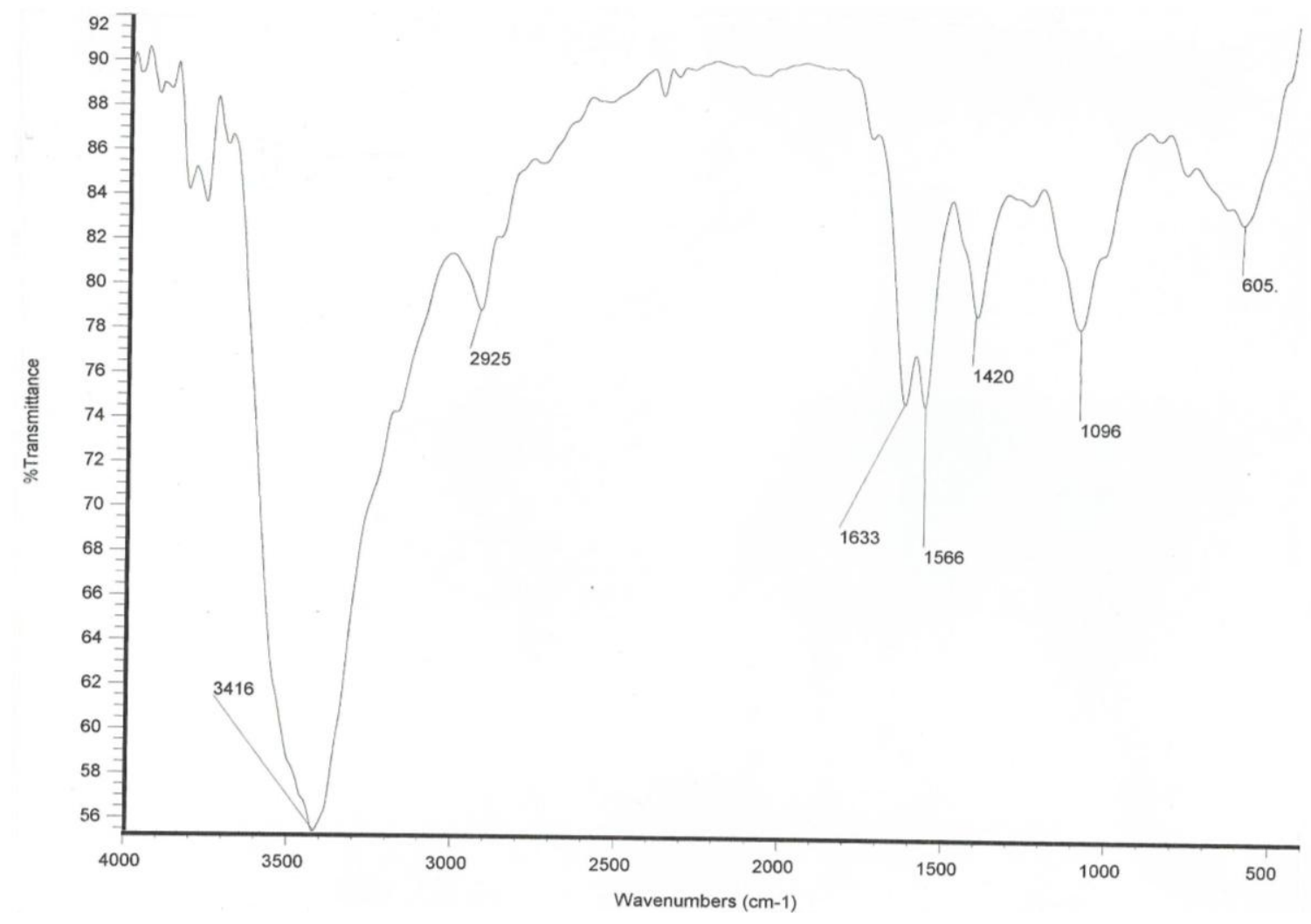

Fig. 4: IR spectra of the major HPLC peak using Perkin Elmer Infrared Spectrophotometer. 


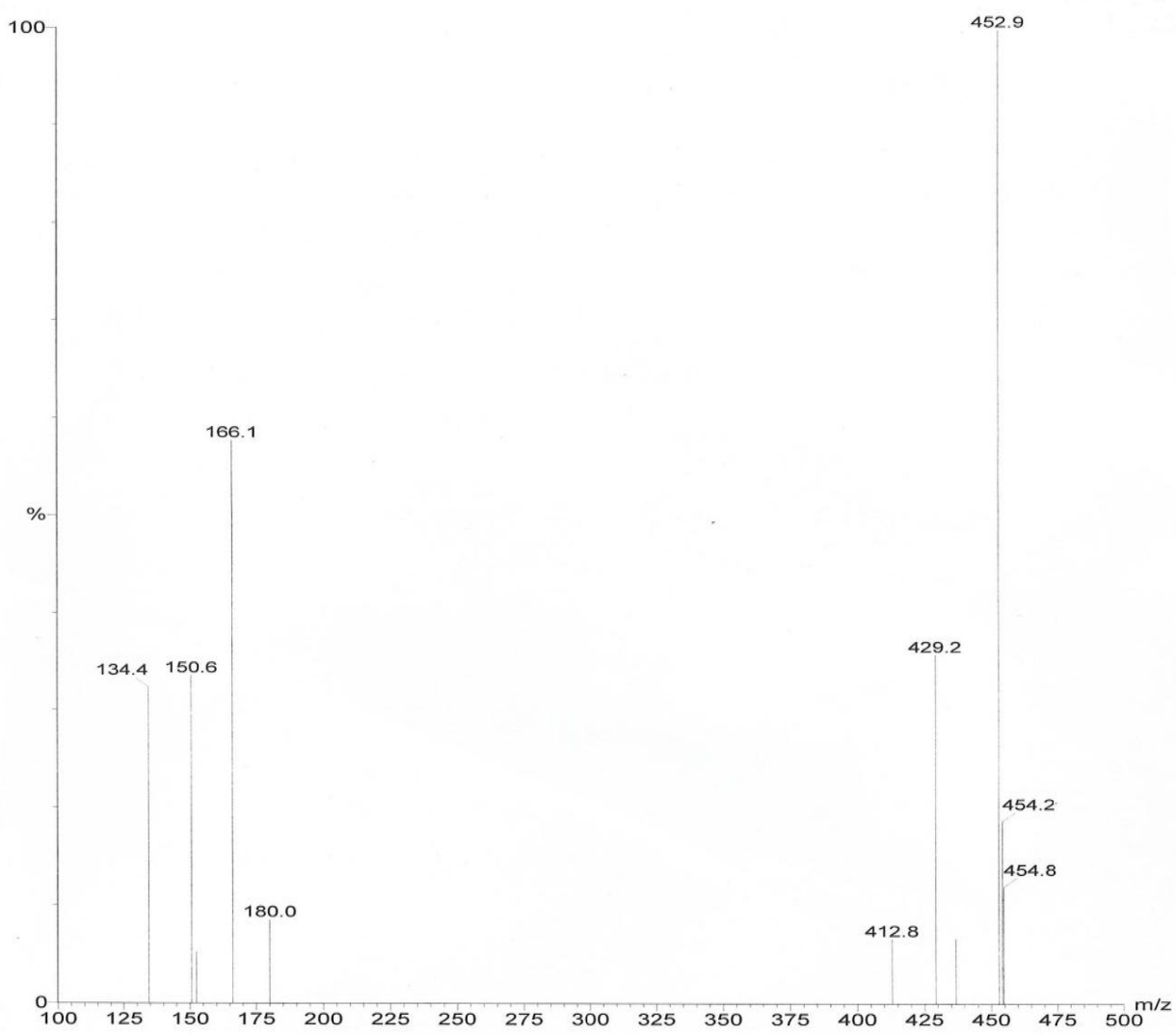

Fig. 5: Mass Spectra of the major peak of HPLC fraction showing $\mathrm{m} / \mathrm{z}$ ratio of 454.8 .

\section{CONCLUSION}

This study was performed to isolate and identify the active fraction possessing AR inhibitory activity from the TP fraction of $P$. fulgens roots. From the biochemical analysis, it confirms that the TP fraction contained polyphenolic and flavonoid group which was separated into different fractions by TLC where fraction F-V was found to have better inhibitory activity against AR compared to the other TLC fractions. The active fraction isolated from $P$. fulgens could be a promising antidiabetic drug as it has the ability to inhibit the aldose reductase of the polyol pathway which is one of the mechanisms leading to diabetic complication.

\section{ACKNOWLEDGEMENT}

The authors acknowledge the Department of Chemistry, NEHU, Shillong for IR spectra and Sophisticated Analytical Instrumental Facility Centre (SAIF), NEHU, Shillong for MS analysis. The authors would like to thanks Mr. J.M. Sohtun for his assistance with the HPLC analysis.

\section{REFERENCES}

Ahmad F, Ali M, Alam P. New phytoconstituents from the stem bark of Tinospora cordifolia Miers. Nat Prod Res, 2010; 24:926-934.
Alexiou P, Pegklidou K, Chatzopoulou M, Nicolaou I, Demopoulos VJ. Aldose reductase enzyme and its implication to major health problems of the 21(st) century. Curr Med Chem, 2009; 16:734-752.

Bradford M.A rapid and sensitive method for the quantitation of mcrogram quantities of protein utilizing the principle of protein-dye binding. Anal Biochem, 1976; 72:248-254.

Brahmachari G, Gorai D. Progress in the research on naturally occurring flavones and flavonols: An overview. Curr Org Chem, 2006a; 10:873-898.

Brahmachari G, Gorai D. 2006b. Progress in the research of natural flavonoids: An overview. In: Brahmachari G, ed. Chemistry of Natural Products: Recent Trends and Developments. Trivandrum: Research Signpost. 78-168.

Brahmachari G. 2009. Mother nature: An inexhaustible source of drugs and lead molecules. In: Brahmachari G, ed. Chemistry, Biochemistry and Pharmacology. New Delhi: Narosa Publishing House Pvt. Ltd. 1-20.

Cappiello M, Voltarelli M, Cecconi I, Vilardo PG, Dal Monte M, Marini I, DelCorso A, Wilson DK, Quiocho FA, Petrash M, Mura U. Specifically targeted modification of human aldose reductase by physiological disulfides. J BiolChem, 1996; 271:33539-33544.

Chandra D, Jackson EB, Ramana KV, Kelley R, Srivastava SK, Bhatnagar A. Nitric oxide prevents aldose reductase activation and sorbitol accumulation during diabetes. Diabetes, 2002; 51:3095-3101.

Chang CC, Yang MH, WEN HM, Chern JC. Estimation of total flavonoid content in propolis by two complementary colorimetric methods. J Food Drug Anal, 2002; 10:178-182.

Costantino L, Rastelli G, Vianello P, Cignarella G, Barlocco D. Diabetes complications and their potential prevention: Aldose reductase inhibition and other approaches. Med Res Rev, 1999; 19:3-23.

Das B, Srivastava SK. Activation of aldose reductase from human tissues. Diabetes, 1985; 34:1145-1151. 
Dick DP, Mangrich AS, Menezes SMC, Pereira BF. Chemical and spectroscopical characterization of humic acids from two South Brazillian coals of different ranks. J Braz Chem Sci, 2002; 13(2):177-182.

Foppiano M, Lombardo G. Worldwide pharmacovigilance system and tolrestat withdrawal. Lancet, 1997; 349: 399-400.

Guzman A, Guerrero RO. Inhibition of aldose reductase by herbs extracts and natural substances and their role in prevention of cataracts. Rev Cubana Planta Med, 2005; 10:3-4.

Gritsenko OM, Smik GK. Phytochemical study of Potentilla alba. FarmatsevtichniiZhurnal (Kiev), 1977; 1:88-89.

Hamada Y, Nakamura J. Clinical potential of aldose reductase inhibitors in diabetic neuropathy. Treat Endocrinol, 2004; 3:245-255.

Hamburger M, Hostettmann K. Bioactivity in plants: the link between phytochemistry and medicine. Phytochemistry, 1991; 30(12):3864-3874.

Haraguchi H, Ohmi I, Sakai S, Fukuda A, Toihara Y,Fujimoto T, Okamura N, Yagi A. Effect of Polygonum hydropiper sulfated flavonoids on lens aldose reductase and related enzymes. J Nat Prod, 1996; 59:443-445.

Haraguchi H, Ohmi I, Fukuda A, Tamura Y, Mizutani K, Tanaka O, Chou WH. Inhibition of aldose reductase and sorbitol accumulation by astilbin and taxifolin dihydroflavonols in Engelhardtia chrysolepis. Biosci Biotechnol Biochem, 1997; 61:651-654.

Harborne JB. 1992. Chemicals as defence agents. In: Harborne JB, ed. Introduction to ecological Bochemistry. New York: Academic Pres. Harcourt Brace and Co publishers. 131-158.

Harborne JB. 1998. Phytochemical methods, 3rd edition, London and New York: Chapman and Hall.

Hulse JH, Laing EM, Perason, OE. 1980. Sorghum and the millets: their composition and nutritive value. London: Academic Press.

Hung HY, Qian K, Morris Natschke SL, Hsu CS, Lee KH. Recent discovery of plant-derived anti-diabetic natural products. Nat Prod Rep, 2012; 29:580-606.

Kim MK, Kim SY, Lee HS.Rat lens aldose reductase inhibitory activities of oriental medicinal plants. Agric Chem Biotechnol, 2001; 45:84-88.

Kombal R, Glasl H. Flavan-3-ols and flavonoids from Potentilla aserina. Planta Med, 1995; 61(5):484-485.

Kudzin SF, Nord FF. Investigations on lignin and lignifications. IV. Studies on hardwood lignin. J Am Chem Soc, 1951; 73(2):690-693.

Lipinski CA, Lombardo F, Dominy BW, Feeney PJ. Experimental and computational approaches to estimate solubility and permeability in drug discovery and development settings. Adv Drug Deliv Rev, 1997; 23(1-3):3-25.

Lindstad RI, Hermansen LF, McKinley-McKee JS.Inhibition and activation studies on sheep liver sorbitol dehydrogenase. Eur J Biochem, 1994; 221:847-854.

Miraliakbari H, Shahidi F. Oxidative stability of tree nut oils. Food Chem, 2008; 111(2):421-427.

Morrison AD, Clements RS, Travis SB, Oski F, Winegrad AI.Glucose utilization by the polyol pathway in human erythrocytes. Biochem Biophys Res Commun, 1970; 40:199-205.

Pathania S, Randhawa V, Bagler G. Prospecting for novel plantderived molecules of Rauvolfia serpentina as inhibitors of aldose reductase, a potent drug target for diabetes and its complications. PLoS ONE, 2013; 8(4): e61327. doi:10.1371/journal.pone.0061327.

Patra JC, Chua BH. Artificial neutral network-based drug design for diabetes mellitus using flavonoids. J Comput Chem, 2010; 32:555-567.

Rao UM, Sreenivasulu M, Chengaiah B, Jaganmohan Reddy K, Chetty MC. Herbal medicines for diabetes mellitus: a review. Int J Pharm Tech Res, 2010; 2:1883-1892.

Rates SML. Plants as source of drugs. Toxicon, 2001; 39:603613.

Reddy GB, Muthenna P, Akileshwari C, Saraswat M, Petrash JM. Inhibition of aldose reductase and sorbitol accumulation by dietary rutin. Curr Sci, 2011; 101(9):1191-1197.
Robards K, Antolovich M. Analytical chemistry of fruit bioflavonoids. A review. Analyst, 1997; 122:11R-34R.

Schemmel K, Padiyara R, D'Souza J. Aldose reductase inhibitors in the treatment of diabetic peripheral neuropathy: a review. J Diabetes Complications, 2010; 24:354-360.

Srivastava SK, Hair GA, Das B. Activated and unactivated forms of human erythrocyte aldose reductase. Proc Natl Acad Sci USA, $1985 ; 82: 7222-7226$.

Srivastava SK, Ansari NH, Hair GA, Awasthi S, Das B. Activation of human erythrocyte, brain, aorta, muscle, and ocular tissue aldose reductase. Metabolism,1986a; 35(Suppl 1):114-118.

Srivastava SK, Ansari NH, Hair GA, Jaspan J, Rao MB, Das B. Hyperglycemia-induced activation of human erythrocyte aldose reductase and alterations in kinetic properties. Biochim Biophys Acta, 1986b; 870: 302-311.

Steele JW, Faulds D, Goa KL. Epalrestat. A review of its pharmacology, and therapeutic potential in late-onset complications of diabetes mellitus. Drugs Aging, 1993; 3:532-555.

Syiem D, Gareth S, Khup PZ, Khongwir BS, Kharbuli B, Kayang H. Hypoglycemic effect of Potentilla fulgens L. In normal and alloxan-induced diabetic mice. J Ethnopharmcol, 2002; 83:55-56.

Syiem D, Syngai C, Kharbuli B, Kayang H, Khongwir BS. Anti-tumor activity of crude root extract of Potentilla fulgens. Indian Drugs, 2003; 40:124-125.

Syiem D, Khup PZ, Syiem AB. Effects of Potentilla fulgens Linn. on carbohydrate and lipid profiles in diabetic mice. Pharmacologyonline, 2009a; 2:787-795.

Syiem D, Sharma R, Saio V. In vitro study of the antioxidant potential of some traditionally used medicinal plants of North-East India and assessment of their total phenolic content. Pharmacologyonline, 2009b; 3:952-965.

Syiem D, Majaw S. Effect of Potentilla fulgens L. aldose reductase activity of normal and diabetic mice. Inventi Rapid: Ethnopharmacology, 2010; 1(1):ep13.

Van den Enden MK, Nyengaard JR, Ostrow E, Burgan JH, Williamson JR. Elevated glucose levels increase retinal glycolysis and Van den Enden MK, Nyengaard JR, Ostrow E, Burgan JH, Williamson JR. Elevated glucose levels increase retinal glycolysis and sorbitol pathway metabolism. Implications for diabetic retinopathy. Invest Ophthalmol Vis Sci, 1995; 36:1675-1685.

Veeresham C, Rama Rao A, Asres K. Aldose reductase inhibitors from plant origin. Phytother Res, 2013; 28(3):317-333.

Vennat B, Bos MA, Pourrat A, Bastide P. Procyanidins from tormentil: fractionation and study of the anti-radical activity towards superoxide anion. Biol Pharm Bull, 1994; 17:1613-1615.

Wagner H, Bladt S. 1996. Plant Drug Analysis: A Thin Layer Chromatography Atlas. 2nd edition. Heidelberg, NY, USA: Springer.

Wrolstad RE, Acree TE, Decker EA, Penner MH, Reid DS, Schwartz SJ, Shoemaker CF, Smith DM, Sporns P. 2005. Handbook of food analytical chemistry: pigments, colorants, flavors, texture and bioactive food components. Hoboken, New Jersey: John Wiley \& Sons Inc. 489

Yabe-Nishimura C. Aldose reductase in glucose toxicity: a potential target for the prevention of diabetic complications. Pharmacol Rev, 1998: 50:21-33.

Yam MF, Lim V, Salma IM, Ameer OZ, Ang LF, Rosadah N, Abdulkarm MF, Abdullah GZ. HPLC and Anti-inflammatory studies of the flavonoid rich chloroform extract fraction of Orthosiphon stamineus leaves. Molecules, 2010; 15:4452-4466.

\section{How to cite this article:}

Suktilang Majaw, Donkupar Syiem. In vitro aldose reductase inhibitory potential of fractions isolated from Potentilla fulgens roots. J App Pharm Sci, 2016; 6 (08): 102-109. 